\title{
Sciendo
}

\section{Taiwanese Identity - Past Factors and Present Circumstances}

\author{
PAWEL SENDYKA
}

Institute of Ethnology and Cultural Anthropology, Jagiellonian University in Krakow, Poland

sendyka@protonmail.com

\begin{abstract}
Taiwan is an island that off the coast of China. To say that Taiwan is a country is to offend the Communist People's Republic of China which claims sovereignty over the island and markets it to the world as a "renegade province" which must be re-united with the mainland, by force, if necessary. For people who know very little about Taiwan and its big neighbour across the Taiwan Strait this may even sound convincing, but the truth is more complex. In 1949 the nationalist government (Kuomintang or KMT) having lost the Chinese Civil War retreated from the mainland; the communists have never ruled the island.

The settling of the Republic of China's government in Taiwan and the era of "White Terror" was another one in a series of historical events that were fundamental in forming the modern Taiwanese identity. Whatever the proponents of "one China" claim, the truth of the matter is that there is a shift in attitudes of the inhabitants of Taiwan in how they feel about themselves (Taiwanese, Chinese or both). This is a crucial fact that will have to be acknowledged in the cross-strait relations. The identity argument as such, is independent of any historical claims. And this Taiwanese identity has been evolving and will continue to do so, shaped by the past and the most recent events like the Hong Kong protests, the pandemic, politics and the military aggression and intimidation by the People's Republic of China. This article will examine these factors in turn.
\end{abstract}

KEY WORDS: COVID-19 pandemic, cross-strait relations, democracy in Asia Hong Kong protests, military intimidation, Taiwanese identity 


\section{Introduction - Historical Perspective - an Overview}

Taiwan is an island roughly 170 kilometers off the coast of southeastern China. It has a rich history, though the recorded part is very brief compared to other Asian countries. People have inhabited the island for thousands of years, arriving in migrations from Asia. Eventually, Chinese settlements appeared. In 1622 the Ming dynasty agreed that the Dutch could have Taiwan (for a more important at the time Penghu Island) and the Dutch traders established forts and proceeded to build a colony. There was a brief a brief Spanish incursion and in 1661 a pirate kingdom of Zheng Chenggong known as Koxinga, a return to the Chinese imperial rule after that and then a Japanese occupation and their colonial rule following the SinoJapanese War and the Treaty of Shimonoseki. Before the arrival of the Japanese troops the Taiwanese made their bid for independence declaring the Republic of Formosa, but its forces were eventually overcome by the Japanese (MANTHORPE 2005).

Taiwan was returned to the Chinese mainland rule when Japan lost in the Second World War. But China has changed a lot during that time. Since 1912 it was called Republic of China and was ruled by Kuomintang (KMT) or Chinese Nationalist Party. They were involved in a fierce civil war with Mao Zedong's communists. Instead of becoming one of the provinces of China it became Republic of China's final outpost when the defeated nationalists of Chiang-Kai-shek and his army finally arrived in 1949. They imposed the mainland culture and Mandarin language on the predominantly Hokkien-speaking majority. The mainland Chinese rulers were often seen as more brutal then the Japanese rule. Even before ChiangKai-shek's arrival around 30000 people were killed in the unrest following the "2-28 incident". The years of the so called White Terror followed.

In 1987 the martial law (which lasted from 1949) was lifted and Taiwan developed into not just into a world's powerhouse producing over $60 \%$ of the of the world's computer chips, (with just one company TSMC, holding over 50\% of the world market share) (LEE 2021) but also into a unique, vibrant and open society. One in which there is a cultural consensus across the board supportive of a Western-style democratic system of governance and antiauthoritarian (HUANG - LIU - CHANG 2004:160). A society, which despite its different origins, after decades of living together, formed what Taiwan's late president Lee Teng-hui (KMT) (1988-2000) called a "community of shared fate" (RIGGER 2011:430) or president Chen Shui-bian's (DPP) (2000-2008) "shared destiny" (RIGGER 2011:451). A fate, or destiny, over which the issue of China always casts a big shadow.

As Barth pointed out, the formation of a distinct identity is accomplished by the setting of boundaries which set a distinction between members and non-members of the group 
Pawel SENDYKA

Taiwanese Identity - Past Factors and Present Circumstances

(BARTH 1969). The old divisions within Taiwan are giving way to a new boundary between the Taiwanese and mainland Chinese.

\section{Taiwanese Identity and Culture}

Although Mandarin is the official language of the Republic of China (Taiwan's formal name) and the KMT regime went to great lengths to implement it after its arrival, it is markedly different from the language used on the mainland.

Besides the accent, and the frequent use of Taiwanese and other dialects to express themselves in different situation, the Mandarin used on the island uses the traditional Chinese characters, not simplified. The Taiwanese also use the original Chinese phonetic alphabet Zhuyin (bopomofo) while the mainland China adopted Roman alphabet based Pinyin.

Instilling in the inhabitants of Taiwan a sense of Chinese identity was of paramount importance to the nationalist KMT government which for the first few decades of its rule was obsessed with the idea of "reunification", for them defined as retaking the mainland from the communists.

The Nationalist Party or Kuomintang (KMT) was a repressive regime. Many of its opponents and detractors have pointed out that it was one more in a series of the colonial rulers which the Taiwanese had to endure. Driven by its ambition to return and retake the mainland, the KMT proceeded to try to dominate and assimilate the Taiwanese society to the ruling party's Chinese origin and world view. They have been successful and have accomplished that through methods of (1) coercion, (2) education, (3) restructuring the social status and (4) creating of a new "pro-Chinese" identity for the indigenous population (CHEN 2008:188). The KMT imposed Mandarin on the Taiwanese speaking majority, while at the same time disallowing the use of Japanese and local dialects in public. Chinese teachers who arrived with Chiang-Kai-shek from the mainland became the school masters and administrators, with the local teachers relegated to supporting roles (CHEN 2008:201). As Chen notes:

"The usual school curriculum included daily flag-raising ceremonies, 5 military training courses, and music lessons on military anthems. Children in the public school system from age 6 to 18 were taught military songs such as 'Fight our way back to the Mainland'. 'I am a Chinese,' 'China will be Strong', 'I love China', and 'The Plum Blossom.' Regular military anthem competitions were held to reward those who can memorize and sing the songs the best" (CHEN 2008:201). 
Clearly, KMT did its very best to instill in the new generation of Taiwanese children a Chinese identity. Mandarin in Taiwan was a language that was imposed on the local population, in that the locals were required to learn Mandarin but the new arrivals were not required to learn the languages of the indigenous groups.

The educational system was also very much skewed against the native Taiwanese. As Taiwan become the seat of the Republic of China government, it became, in theory, an ark for all the people of the mainland which had 35 provinces before the civil war. Students admissions to high schools and universities were based on the provincial origin, which ensured more spots for the mainland Chinese at better schools and universities. 'For example, if 35 individuals were admitted to a school, 34 of them would be from provinces in China and only one person would be Taiwanese since Taiwan was treated one of the provinces' (CHEN 2008:203).

Similarly, the KMT also did its best to impose the Chinese culture on the local population. Today, as the author of this article can personally attest, Mandarin is the official and the dominant language in Taiwan, with many younger generations Taiwanese feeling more comfortable with speaking Mandarin then in their once native tongue.

Taiwan today, despite (or maybe because of) its authoritarian past and decades long martial law is now a vibrant, diverse and tolerant democracy. In May of 2019 it became the first country in Asia to legalize same-sex marriage. This open society and its way of life is very different to what goes on on the opposite side of Taiwan Strait. As one of my informers had said, proximity of China is both Taiwan's great misfortune and great luck. The misfortune part is obvious: the constant threat it poses. The luck part comes from having as one looks across the strait, it becomes apparent in which direction Taiwan should never go and which way it should move. Every day, the Taiwanese construct their identity acknowledging the Chinese history, language and culture, but at the same time in direct opposition to China today as embodied by the Chinese Communist Party authoritarian rule.

\section{Taiwanese Identity and Politics}

Today the question of identity Taiwanese versus Chinese is an issue that is influenced by Taiwan's uncertain international status. Taiwan is not recognised as a country by most nations - with no official relations, exchange of ambassadors or a seat in international organizations such as the UN or the WHO. That is the matter of theory. In practice, many countries including the United States have de facto embassies there. Taiwanese passports are accepted internationally and enjoy a reciprocal generous visa-free stay periods with many 
countries and the EU. Amid the coronavirus pandemic the government in Taipei changed the design of Taiwanese passport to emphasize 'Taiwan' and shrunk the 'Republic of China' label (The New Your Times n.d.). Although the Taiwan government officials said the redesign was an attempt to disassociate Taiwanese citizens from the citizens of the mainland who faced travel restrictions amid the pandemic, this and the re-branding of the Taiwanese warships is similar to the re-naming of all the state owned corporations which had 'China' in the name during the president's Chen Shui-bian administration (Taiwanese national carrier is still called China Airlines though). Both Chen Shui-bian and the current president Tsai Ingwen are from the same Democratic Progressive Party which is more pro independence and less pro-unification than the KMT. The passport redesign could also be seen as one more way not just to shore up international recognition of Taiwan but to try to reflect (or influence, depending on your point of view) the national identity. Of course, officials in Beijing, predictably, react angrily to such moves restating their mantra that this would not change Taiwan being an "inalienable part of China" as mouthed by the foreign ministry spokeswoman (BBC News n.d.).

One thing is certain. Taiwanese identity is something that is important for both the internal and external politics and although the Chinese and Taiwanese identity need not to be mutually exclusive especially in cultural sphere, they are becoming increasingly so in the political context and it will weigh in heavily on any future unification with the mainland project.

\section{Taiwanese Identity - Trends}

Since 1992 National Chengchi University's Election Study Center has been conducing regular polls on how the citizens of Taiwan self-identify (Figure 1):

Before discussing the information presented in this diagram it is important to note that these surveys were started in 1992 which was the year that the first free and fair legislative elections took place. And that in 1996, the year after which the "Taiwanese only" choice spikes up from 24 to $34 \%$ was the year that the first fully democratic presidential election was held (and it was also the year, in which, the People's Republic of China attempted, for the first time in years to intimidate Taiwan by firing missiles which crossed the middle of the Taiwan Strait). 


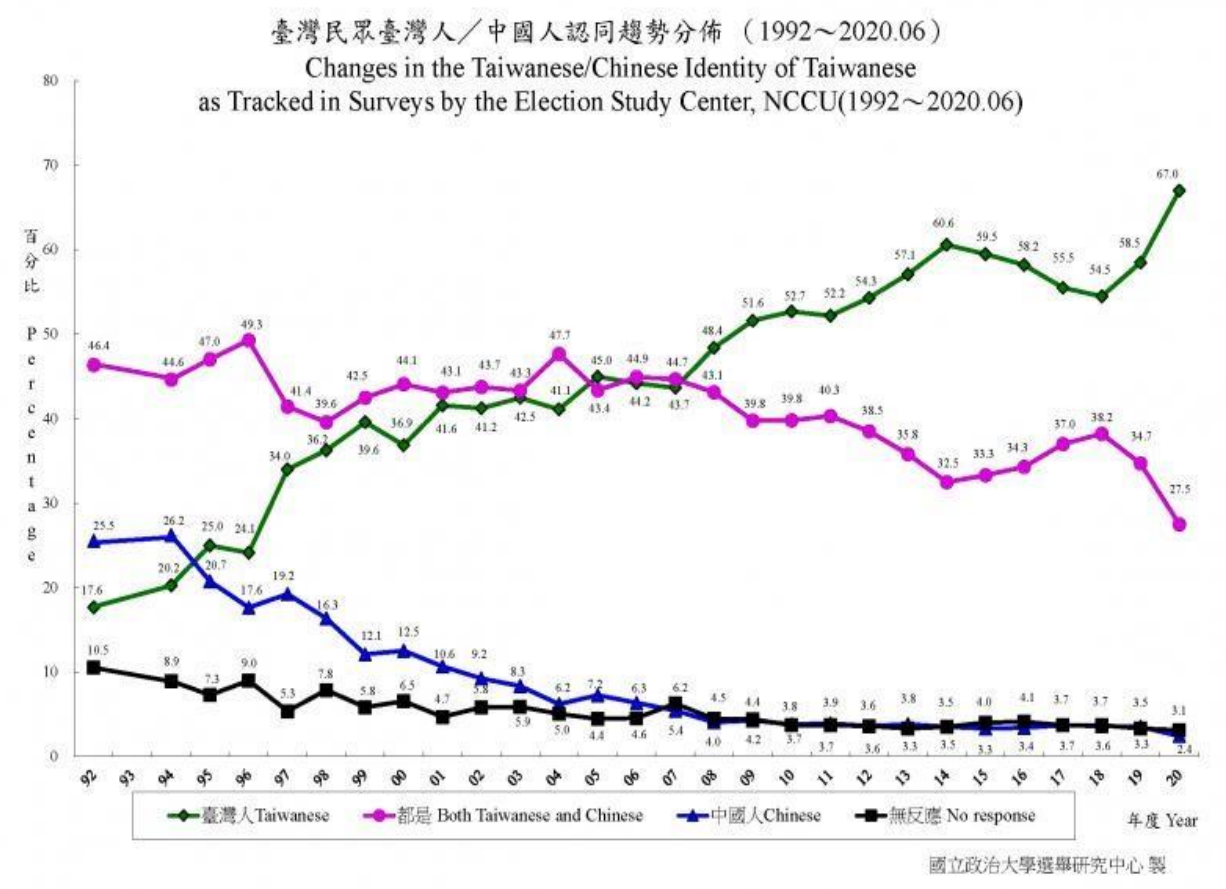

Figure 1: Changes in the Taiwaneese/Chinese Identity of Taiwanese as Tracked in Surveys by the Election Study Center. Source: Election Study Center National Chengchi University n.d.

It is interesting to note the trends on this graph. Given the options of identifying as Taiwanese, Chinese or both, since 1992 when the polls were first conducted there has been a dramatic shift in identity over the last 2 decades. In $199222.5 \%$ of respondents identified themselves as Chinese only, much higher percentage than the $17.6 \%$ for Taiwanese only response $46.4 \%$ identified as both Taiwanese and Chinese. In the latest poll of 2020 the selfidentification as Taiwanese stands at a record-high $67 \%$, while the Chinese-only identification dropped down to $2.4 \%$. Those who identify themselves as both stand at $27.5 \%$.

It is interesting to note that the Taiwanese-only self-identification has been rising steadily for the entire period and it matched the "both Chinese and Taiwanese" identification in the 20052007 period where they both stood at around $45 \%$. The self identification as Chinese only has been dropping for the period under review, from just over 25\% in 1992 and reaching $5.4 \%$ in 2007. 
From 2008 onward the increase in the Taiwanese-only identity seems to be at the expense of the both Chinese and Taiwanese identity choice. No doubt political events that have taken place during that time have had an influence over this identity shift.

The political events formative for the Taiwanese identity in general will be discussed in the next section as well as this author's propositions as to which recent developments might have have been influential in the recent shifts in the Taiwanese identity.

\section{Formative Events - Past}

Huang, Liu, and Chang conducted a survey of which events in the Taiwanese history were considered formative by both those who identified as Chinese and Taiwanese (HUANG LIU - CHANG 2004). Both groups were in agreement that the following events were of seminal importance:

\section{The 2-28 Incident (February 28, 1947)}

After the Second World War, Formosa (as the island was then known as) was returned to China, then ruled by the nationalist party or the KMT with Chiang Kai-shek as its leader. It happened after five decades of the Japanese colonial rule. Not even full two years later, the local Taiwanese inhabitants revolted. They demanded a greater degree of autonomy, some even self-rule or placing the island of Formosa under UN's international mandate and arguing that China had no more historical claim to Formosa than the Japanese, Dutch or Portuguese (DURDIN 1947). The Formosans have taken over the island and the KMT local representative Chen $\mathrm{Yi}$ feigned talks while waiting for the reinforcements from the mainland to arrive. The uprising was then brutally suppressed with horrible atrocities committed and the number of the dead estimated between 18,000 to 25,000 with the official KMT documentation 'lost'. This 2-28 Incident of 1947 when a local elite was physically eliminated, was a formative event for the struggle of the Taiwan independence movement and so in the creation and formation of a Taiwanese identity (FLEISCHAUER 2007).

As Huang, Liu, and Chang note, no matter the self-identification, the 2-28 Incidents is viewed by all as both important for the nation and also as unequivocally a negative event (HUANG - LIU - CHANG 2004). 


\section{Kaohsiung Incident of 1979 (also known as Meilidao Incident or Formosa Magazine} Incident)

On December 10 of 1979, the year when the United States switched its recognition from Taipei to Beijing, during the period of the martial law, the opposition activists associated with the opposition Formosa Magazine organised a rally in Kaohsiung. The organisers, known as the Kaohsiung Eight were arrested after giving speeches. One of those was Annette Lu. She was sentenced, together with the rest of the Kaoshiung Eight to a lengthy, 12-year prison sentence (CHEN 2008). The Meilidao Incident is also perceived as one of the seminal events in the modern Taiwanese history and it is perceived as one of the events that eventually led to a democracy. As Huang, Liu and Chang point out, this crackdown on the freedom of press is judged in itself negatively but not as unambiguously as the 2-28 Incident (HUANG - LIU - CHANG 2004). This is because although the people who took part in it suffered, they also "planted the seeds for democracy". One of the lawyer's on Annette Lu's defence team was an inexperienced maritime law expert Chen Shui-bian (MANTHORPE 2005:15). In 2000 Chen-Shui-bian became the first non-KMT president and Annette Lu became his vice president.

\section{The End of the Martial Law in 1987}

The martial law was introduced in 1947. It lasted for almost 4 decades with the KMT insisting it is because Taiwan is under a constant threat of invasion from the communist mainland (MANTHORPE 2005:203). After the 2-28 Incident, the decades of "White Terror" followed where dissenters and people suspected of being disloyal to KMT's vision of China, were being labelled as communists. Estimates vary, because official records were destroyed, but they go into tens of thousands of victims. Some estimate as many as 90,000 people were arrested during those years with about 10,000 of those actually tried in military courts and about 45,000 simply executed without any process (MANTHORPE 2005:204).

With the end of the martial law the opposition Democratic Progressive Party (DPP) could finally be established. The one party state was no more. KMT would no longer be an alien regime but became one of the political parties which would have to compete for votes of the island's inhabitants in whose hands, the future of the nation would ultimately rest. It is not surprising that this event is especially important from the identity point of view as most of the citizens of the island did not see themselves as "province of China". 
Pawel SENDYKA

Taiwanese Identity - Past Factors and Present Circumstances

\section{The First Free Presidential Elections of 1996}

In March of 1996 the first free presidential election in Taiwan took place. It should be mentioned that this important event was not just an internal, Taiwanese affair, but that it was preceded by the Chinese missile tests which, for the first time since 1949, flew across the middle of the Taiwan Strait (CHUANG 2017). The communist Chinese were worried that that these free elections might be a stepping stone to Taiwan formally declaring independence and decided to use this show of force to affect the vote. This 1995-1996 Taiwan Strait Confrontation highlights an important fact about Taiwanese identity. It is not just affected by what the Taiwanese feel about themselves but how they feel about themselves in relation to their big and increasingly powerful, both economically and militarily, neighbor.

\section{Year 2000: The Transfer of Power from the KMT for the First Time}

Despite the lifting of the martial law in 1987, it was only in 2000 that Chen Shui-bian has won the popular elections and became the first non-KMT president. The issues of Chinese and Taiwanese identity have been ever present in the campaign and later during his presidency.

\section{Formative Events - Present}

The current world and domestic events continue to shape the way the inhabitants of Taiwan identify themselves. I would argue that the following recent events would have an impact on now the Taiwanese view and feel about themselves: Hong Kong protests, the pandemic, local politics and the re-election of DPP president Tsai Ing-wen for the second term and lastly the military aggression and intimidation by the PRC.

\section{Hong Kong Protests}

When the pro-democracy protests in Hong Kong erupted in 2019, the whole world was watching, but the Taiwanese were watching especially closely. Hong Kong was the handed over by the British to Beijing in 1997 and as part of that agreement the democratic rights of the Hong Kongers were supposed to be respected. The so called "one country, two systems" principle, where there would be "one China" but Hong Kong and later Macau (which was handed over by Portugal in 1999) would be Special Administrative Regions of China 
guaranteed that they could retain their economic and administrative systems, continue to have their own governments, be able to manage their own legal, economic and financial affairs, including trade with other countries independently. This principle was coined during the negotiations with the British and it was touted as a model for a future unification with Taiwan. This "one country, two system" offer for unification was reiterated by Xi Jinping during the National Day address in 2019. This offer though did not sound like an offer at all, but rather like an ultimatum because it is backed by the threat of a military resolution of the issue which the CCP has written into PRC constitution. As such, this "offer" is unacceptable to the Taiwanese, even to the KMT, who has throughout its history been the proponent of merging with the mainland (although in its early years on the island it imagined it would be the one retake it from the communists by force). In 1992, when the KMT was in power, it negotiated with the PRC to help establish a strange, cross-strait consensus of in which the parties agreed that there was one China, but with each side having its own interpretation of what that meant.

What the PRC's president's "offer" fails to notice or acknowledge are the wishes of the Taiwanese people who have seemingly nothing to gain by being ruled by Beijing and everything to lose as the example of Hong Kong has clearly demonstrated. In less than twenty five years since becoming a Special Administrative Region of the PRC, the Hong Kongers saw their rights, which were supposed to have been guaranteed by the treaty with Britain, being taken away. The massive protests of 2019 were the final throes of opposition after which a draconian security law was introduced.

The Taiwanese watched the events unfold in Hong Kong closely, both the ruling elites and the regular citizens. It provided a voyeuristic peek into the future of Taiwan if it ever agreed to the PRC's coercive offer. It also provided a clear exemplification of the differences between People's Republic of China and Republic of China and most probably was one of the factors that served to strengthen the Taiwanese identity at the expense of the both Taiwanese and Chinese one, as evidenced by the aforementioned graph.

The Taiwanese most recent, post-war history and the White Terror era, provides all the experience, still in living memory of many, of what it is like to live under a totalitarian regime. This created a society in which democracy is taken seriously by its citizens.

\section{Covid-19 Pandemic}

As the world is over the year into the global coronavirus pandemic, it is almost hard to believe that there is one country on earth that has managed to prevent the disaster from happening and enjoys a pre-pandemic life in what has been dubbed a 'bubble of normality' (QUIN -

DOI: 10.2478/eas-2021-0013 C University of SS. Cyril and Methodius in Trnava. All rights reserved. 
CHANG CHIEN 2021). This country is Taiwan. And its success stems from two sources. One is the painful experience of the 2003 SARS outbreak with which, because of its international isolation by the People's Republic of China, Taiwan had to contain by itself. Since that time, there procedures established at the ports of entry like routinely monitoring body temperature of those disembarking from the air planes. The other factor was a distrust of the official statements coming from the PRC. Having been blocked by PRC from the membership in WHO, anything Taiwan could learn had to be second hand from its friends and allies. Based on the information it received from its own experts it sent to Wuhan, Taiwan was the first warn the WHO that the novel coronavirus could most likely transmit from person to person. But, to the world's detriment, it was ignored. The WHO did not acknowledge that fact until much later.

Meanwhile, in Taiwan, the preparation for the possible outbreak moved into full swing in early January 2020. Visas for tourists from Wuhan were cancelled, new production lines for face masks were installed in record time and army used its resources to man them (WANG NG - BROOK 2020:1342). There were no lockdowns but school holidays after the Chinese New Year were extended by 2 weeks to counter the possible spread. Other measures were introduced too. Everyone using public transport system, the trains and the busses was asked to wear a mask - a measure that is still in effect until today.

The effects of government actions and social compliance speak for themselves. Today, Taiwan has no local transmissions of the disease and the majority of its cases are imported from abroad and caught in the quarantine period of 14 days that the visitors to the island are now subject to. As of writing of this article (end of April 2021), there were a total 1110 cases so far and 12 deaths ("Taiwan Centers for Disease Control" n.d.).

What is important to notice about these measures is that not only they were highly effective, but to be so they have required a high degree of social cohesion and trust in what the government was doing and how. The government did its best to communicate openly with the public and to counter misinformation about the pandemic (WANG - NG - BROOK 2020:1342). In fact the trust rating in the government soared and became one of the factors that helped Tsai Ing-wen get re-elected (NACHMAN 2020). Another important factor, from the identity politics point of view is that this pandemic again helped to underline the differences between the Republic of China on Taiwan and the People's Republic of China on the mainland. Taiwan handled the outbreak much better than the mainland, despite being on PRC's doorstep and having the importation risk assessed to be as high as that of South Korea (WANG - NG - BROOK 2020:1341). 
It's handling of the pandemic sets Taiwan apart and shows that an authoritarian system is not necessary for combating the outbreak. It also shows that a democracy, whose people can trust the government, is much better at handling a public health crisis such as the Covid-19 pandemic. It undermines the CCP narrative that "western values" are not appropriate for Asians and that its authoritarian surveillance state is superior.

The pandemic became another focal point in which the Taiwanese got to compare themselves to the mainland Chinese. It brought into focus the differences between the two sides across the Taiwan Strait.

\section{Second DPP Presidency}

In 2016 Tsai Ing-wen became the first woman and a second president of Taiwan to have come from the Democratic Progressive Party, which is more pro-independence than KMT. The Beijing rulers reacted by ending formal direct dialogue with Taiwan, flying bombers around the island and continued efforts to chip away at the few remaining countries which formally recognise Taiwan. During her first term, 7 countries withdrew their formal recognition of Taiwan: Sao Tome and Principe, Panama, Dominican Republic, Burkina Faso, El Salvador, the Solomon Islands and Kiribati (Taipei Representative Office Bratislava n.d.).

In 2020 she was re-elected. The election was watched closely by Beijing with the usual military intimidation tactics which included sailing of a newly constructed aircraft carrier into the Taiwan strait in an effort to influence the voters away from the DPP (Reuters n.d.) After the election Beijing vowed to bring down the total of Taiwan's diplomatic allies to zero (Taipei Representative Office Bratislava n.d.). Every election, China becomes an electoral issue and the behaviour of the Chinese Communist Party does not seem to be helping its cause of unification and is only pushing Taiwanese people away and makes them feel more and more separate from the mainland which doubles down on flexing its military muscles and threats. During the most recent electoral campaign Tsai directly acknowledged the threat of the China as an electoral issue and took out a front-page advertisement in a widely circulated Liberty Times: "In the face of China, every ballot has power," accompanied by a picture of Tsai wearing a camouflaged military helmet and jacket (Reuters n.d.). Meanwhile the Australian press reported on the revelations by the self-professed Chinese spy who sought asylum in Australia of how he was ordered to influence the Taiwanese election in favour of the Communist Party preferred KMT candidate Han Kuo-yu, coupled with his revelations of his role in the kidnappings of the owners of the Cosway Bay Books bookstore and whisking them off to the mainland (60 Minutes Australia n.d.). 
It makes sense that these developments do not only affect the current electoral decisions but underline the critical differences between People's Republic of China and Republic of China, their core values and the way the the inhabitants of the island feel about themselves, their Taiwanese versus Chinese identity. The results of the survey (Election Study Center National Chengchi University n.d.) show this is what is happening and it is also reflected in the preliminary interviews I have conducted. Younger generations feel themselves to be overwhelmingly Taiwanese. How China looms over not just the politics but on the identity of the Taiwanese can be illustrated by one subject's response to why he feels both Taiwanese and Chinese (with a Chinese identity holding a minority, self-ascribed $20 \%$ share). The subject, in his early twenties, said that he feels this way because of the culture and history, but predominantly it reflected a somewhat fatalistic view of the Taiwanese situation that China may be this island destiny and future, and that the United States, whom he described as Taiwan's "sugar daddy" may not always be around or decide to step in to defend the island.

A Taiwanese woman in her fifties identified herself as Chinese only but when pressed further on how she would explain that to a foreigner, who might think she is a Chinese from China (where her parents were from) or from Taiwan, she pondered this question and shook her head "No," she said, "Just Chinese, doesn't matter from where." There is not just a political, but also cultural aspect at play here.

A 2005 informal survey of university students about their identity (Chinese, Taiwanese or both) showed that there is a strong connection between how the question was interpreted and the answered that were given. Those who interpreted the question as "where were you born and raised" tended to favor "Taiwanese" while those who thought the question refers to "cultural and historical background" tended to choose "both Taiwanese and Chinese". "That finding suggests that while many Taiwanese recognize their Chinese cultural heritage, their geographical (and by extension political) connection is to Taiwan. Meanwhile, the PRC's rising prominence - both internationally and in Taiwan's economic life - has strengthened the association between "China" and "People's Republic of China" and made it even less likely that Taiwanese will claim a "Chinese" identity (RIGGER 2011:108).

\section{Military Aggression and Intimidation}

As was mentioned before, the median line across the Taiwan Strait was not crossed from 1947 until 1995 when the Taiwanese embarked on their journey towards the western-style democracy with the first free presidential election in 1996 approaching. Beijing fired its missiles. Since then things have become much worse. 
According to a government report on Chinese People's Liberation Army by the Taiwanese Institute for National Defense and Security Research the incursions into Taiwanese air space in 2020 were the highest since 1996. Chinese craft entered Taiwan's air defence identification zone (ADIZ) on 91 days from Jan. 1 to Nov. 30. Since then, the situation has worsened with almost daily incursions which send the Taiwanese fighter jets into the air each time. It is speculated that China tests Taiwanese defences in preparation for the future invasion, while also wearing down Taiwanese fighter jets, which, like all aircraft have only so many flight hours expectancy. It also keeps the pilots from doing other activities and training that would improve their fighting ability (DW News 2020).

This fact that the Taiwanese democracy is under constant threat of being "liberated" by the Chinese authoritarian regime is always present not only Taiwanese political life but also forever in the minds of the island's inhabitants and is a factor that influences the identity.

\section{Conclusions}

With every poll taken since 1992 the inhabitants of Taiwan weigh in more and more on the Taiwanese side of the Taiwanese, Chinese or both, identity question. The poll in May 2020 reached a record high. As past ethnic divisions are becoming less and less important to the younger generations the 'community of shared fate' is becoming a reality. This community has come a long way from the long martial law by the KMT to a democratic and open society, but every time it looks across the Taiwan Strait, it sees another society under an authoritarian rule with values which are not in line with its own. Taiwan has overcome its own horrific authoritarian past under Chiang Kai-shek and the KMT regime and within it, there is a cultural consensus across the board supportive of a Western-style democratic system of governance and anti-authoritarian.

Today, new regional and world developments such as the pandemic and the military intimidation by the People's Republic of China continue to increase the feeling of separate Taiwanese identity.

\section{Bibliography}

BARTH, Frederic (1969): Ethnic Groups and Boundaries: The Social Organization of Cultural Difference. Boston: Little, Brown and Company. 
CHEN, K. W. (2008): Disciplining Taiwan: The Kuomintang's Methods of Control during the White Terror Era (1947-1987). In Taiwan International Studies Quarterly 4 (4), pp.: 185-210.

CHUANG, Ya-chung (2017): Taiwanese Identity in Global/Local Context: The Use and Abuse of National Consciousness in Taiwan. In Christian Aspalter (ed.): Understanding Modern Taiwan: Essays in Economics, Politics and Social Policy. London: Routledge, pp. 53-65.

DURDIN, Tillman (1947): Formosa Killings Are Put at 10,000. Foreigners Say the Chinese Slaughtered Demonstrators without Provocation. In New York Times, 1947. https://www.taiwandc.org/hst-1947.htm.

FLEISCHAUER, Stefan (2007): The 228 Incident and the Taiwan Independence Movement's Construction. In The Documentation and Research for Modern China 21 (3), pp 373-401.

HUANG, Li Li - LIU James H. - CHANG Maanling (2004): The Double Identity' of Taiwanese Chinese: A Dilemma of Politics and Culture Rooted in History. In Asian Journal of Social Psychology 7 (2), pp. 149-168.

MANTHORPE, Jonathan (2005): Forbidden Nation. A History of Taiwan. London: Palgrave MacMillian.

RIGGER, Shelley (2011): Why Taiwan Matters: Small Island, Global Powerhouse. Lanham, Boulder, New York, Toronto, Plymouth, UK: Rowman \& Littlefield Publishers, Inc.

\section{Internet Sources}

60 Minutes Australia. n.d. "WORLD EXCLUSIVE: Chinese Spy Spills Secrets to Expose Communist Espionage|60 Minutes Australia - YouTube." Accessed April 26, 2021. https://www.youtube.com/watch?v=zdR-I35Ladk.

DW News. 2020. “Taiwan: China's next Target?” September 19, 2020. https://www.youtube.com/watch?v=VkuNWDG3yNM.

Election Study Center National Chengchi University. n.d. "NCCU-Taiwanese/Chinese Identity." Accessed April 27, 2021.

https://esc.nccu.edu.tw/PageDoc/Detail?fid=7800\&id=6961.

Reuters. n.d. "Taiwan to China: Don't Read Too Much into Election Results | Voice of America - English.” Accessed April 26, 2021. https://www.voanews.com/east-asiapacific/taiwan-china-dont-read-too-much-election-results. 
LEE, Yen Nee (2021): "2 Charts Show How Much the World Depends on Taiwan for Semiconductors." CNBC. March 15, 2021. https://www.cnbc.com/2021/03/16/2-chartsshow-how-much-the-world-depends-on-taiwan-for-semiconductors.html.

NACHMAN, Lev (2020): The Year of Unexpected Successes in Taiwan. December 30, 2020. https://www.eastasiaforum.org/2020/12/30/the-year-of-unexpected-successesin-taiwan/.

QIN, Amy - CHANG CHIEN, Amy (2021): Covid? What Covid? Taiwan Thrives as a Bubble of Normality. The New York Times. March 13, 2021. https://www.nytimes.com/2021/03/13/world/asia/taiwan-covid.html.

Taipei Representative Office Bratislava. n.d. "Minister Vows No Fewer Diplomatic Allies in Tsai's Second Term." Accessed April 27, 2021. https://www.roctaiwan.org/sk_en/post/2268.html.

Taiwan Centers for Disease Control. n.d. Accessed April 27, 2021. https://www.cdc.gov.tw/En.

The New York Times. n.d. "Taiwan's New Passport Shrinks 'Republic of China." Accessed April 15, 2021. https://www.nytimes.com/2021/01/11/world/asia/taiwan-newpassport.html.

WANG, C. Jason - NG, Chun Y. - Brook, Robert H. (2020): Response to COVID-19 in Taiwan: Big Data Analytics, New Technology, and Proactive Testing. In JAMA - Journal of the American Medical Association, March 3. Accessed April 26, 2021. https://jamanetwork.com/journals/jama/fullarticle/2762689.

Pawel SENDYKA is a PhD. candidate in anthropology at the Jagiellonian University in Krakow, Poland. His research interests include myth, storytelling and identity. Recent additions to those interests are political anthropology and cross-strait relations (between Taiwan and People's Republic of China). He is research assistant for 'Ecologies of Citizenship: Reviving Pastoralism in the Polish Carpathians', John Fell Fund, University of Oxford (20152016). Once upon a time he works as a cameraman and editor for Channel 7 Australia and he taught anthropology students how to make ethnographic films.

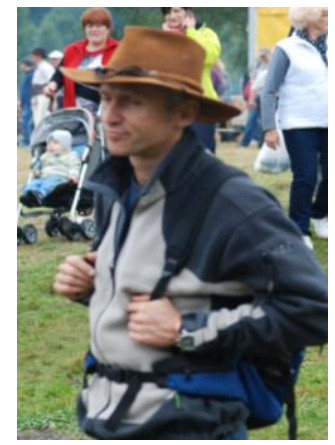

